\title{
Oral Inflammatory Myofibroblastic Tumor: Case Report and Review of Literature
}

\author{
Nada O. Binmadi ${ }^{\mathrm{a},{ }^{*}}$, Harold Packman $^{\mathrm{b}}$, John C. Papadimitriou $^{\mathrm{c}}$ and Mark Scheper ${ }^{\mathrm{a}}$ \\ ${ }^{a}$ Department of Oncology and Diagnostic Sciences, Dental School, University of Maryland, Baltimore, USA \\ ${ }^{b}$ General Dentist, Private practice \\ ${ }^{c}$ Department of Pathology, University of Maryland, Baltimore School of Medicine
}

\begin{abstract}
Inflammatory myofibroblastic tumor (IMT) is a rarely described tumor of unknown etiology and pathogenesis. It occurs primarily in the lungs, but has occurred in other extra-pulmonary sites. Histologically these lesions appear as an inflammatory infiltrate within a variably myofibrotic background. Current evidence shows that inflammatory myofibroblastic tumors are neoplastic processes resulting from chromosomal translocations that often cause an overexpression of ALK kinase, which is often assessed using immunohistochemical studies. Currently, the biological behavior of oral inflammatory myofibroblastic tumor is still uncertain. This article describes the clinical, histological, and operative features of a case of IMT of the oral cavity.
\end{abstract}

Keywords: Inflammatory myofibroblastic tumor, inflammatory pseudotumor, oral cavity.

\section{INTRODUCTION}

Inflammatory Myofibroblastic tumor (IMT) is a rare neoplasm consisting of variable numbers of inflammatory cells and myofibroblastic spindle cells. It was first observed in the lung and described by Brunn in 1939 and was so named by Umiker et al. in 1954 because of its clinical and radiological behavior that mimics a malignant process [1]. The most common sites of involvement include the lung, liver and orbit, but it has been reported to occur in nearly every site of the body, including the major salivary glands and the oral cavity [1-4]. It was called inflammatory pseudotumor (IPT) until 1998 when the term inflammatory myofibroblastic tumor (IMT) was proposed as being a more descriptive name [1]. The etiology and pathogenesis of IMT remains unclear. Because it can clinically and radiographically mimic a malignant process, the correct recognition of the lesion is important to avoid unnecessary radical surgery. Herein, we describe the clinicopathologic features of a case of IMT arising in the gingiva.

\section{CASE REPORT}

A 40-year old female presented with a several month history of slow growing, painless nodule in anterior maxillary gingiva. The lesion was a well circumscribed, raised sessile nodule, the same color as the surrounding mucosa, in the

*Address correspondence to this author at the Oral and Maxillofacial $\mathrm{Pa}$ thology, Department of Oncology and Diagnostic Sciences, Dental School, University of Maryland, 650 W. Baltimore St, 7 North, Baltimore, 21201 MD, USA; Tel: 410706 1655; Fax: 4107060519 ;

E-mail: nbinm001@umaryland.edu

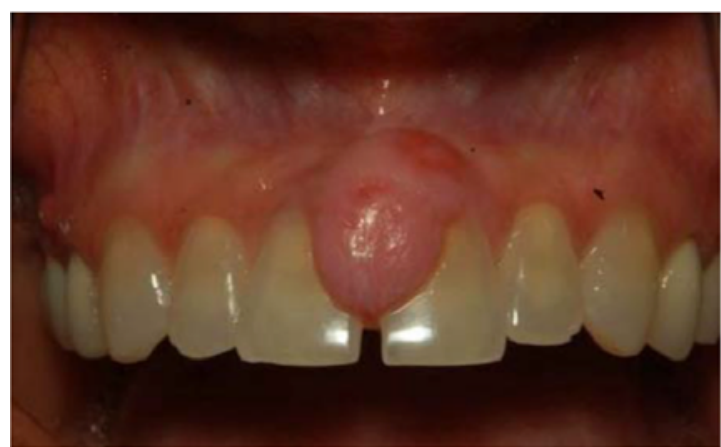

Fig. (1). Intraoral photograph at the initial examination. A 15-mm painless nodule was observed on anterior maxillary ginigiva.

area between teeth numbers 8 and 9 (Fig. 1). There was no bleeding or exudates in the area. The patient's medical and social history was non-contributory and she did not take any medications. Radiographic examination was unremarkable. The initial clinical differential diagnosis was pyogenic granuloma, fibroma, peripheral giant cell lesion and peripheral ossifying fibroma.

The lesion was excised and submitted to the Oral Pathology Department at the University of Maryland, Baltimore. Gross examination of the specimen revealed a tan soft tissue mass, measuring $1.5 \times 1.1 \times 0.7 \mathrm{~cm}$. Microscopic examination of the soft tissue specimen, using hematoxylin and eosin stain, revealed a mixture predominately composed of inflammatory cells, with scant irregularly arranged fascicular spindle cells mixed with a prevalent plasma cell infiltrate (Fig. 2A, B). The inflammatory infiltrate also contained varying numbers of neutrophils, lymphocytes and macrophages. The background stroma showed focal myxoid and 


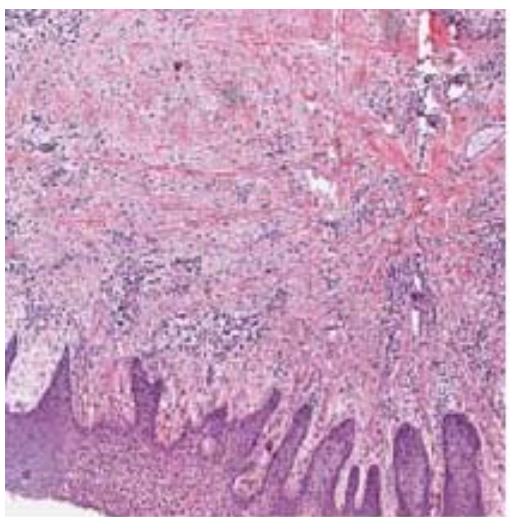

A

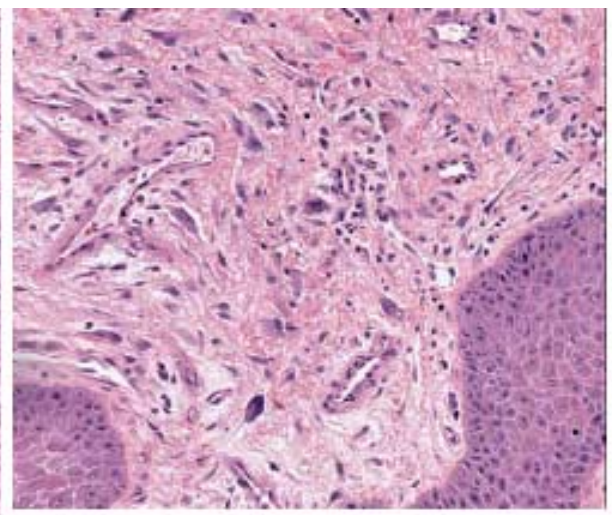

B

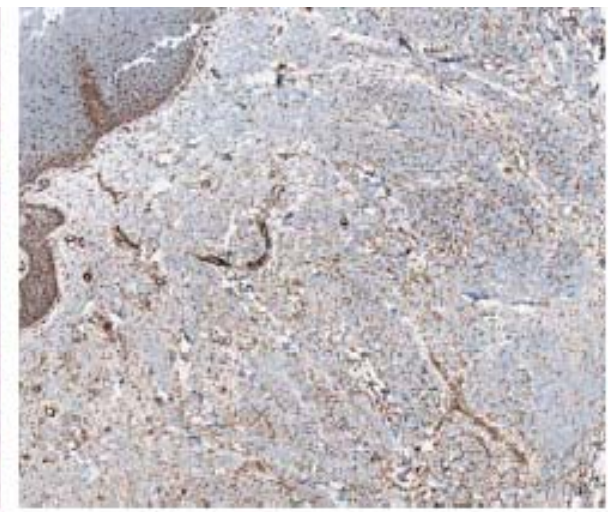

$\mathrm{C}$

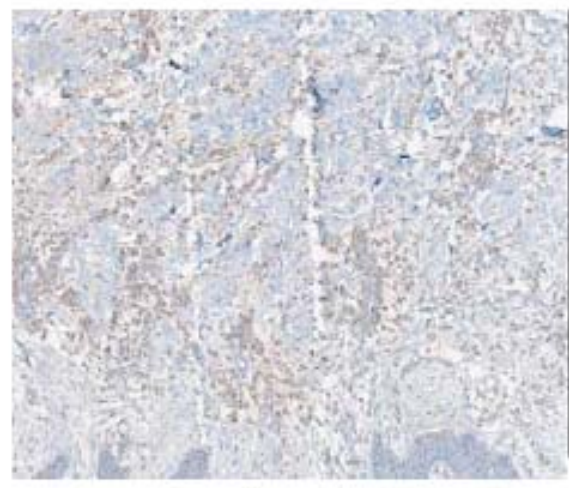

$\mathrm{D}$

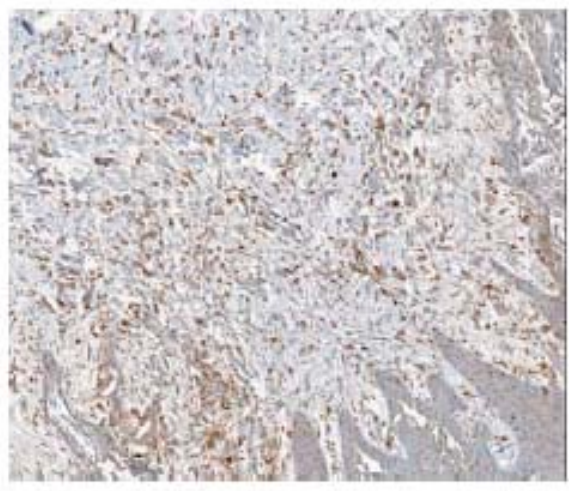

$\mathrm{E}$

Fig. (2). A,B) Low and high power views of the lesion, showing a proliferation spindle cells admixed with numerous chronic inflammatory cells (neutrophils, lymphocytes, macrophages and plasma cells) in a fibrous and myxoid background (hematoxylin and eosin, original magnification X4 and X20). C) Low power view of the immunohistochemical expression for smooth muscle actin showing positive spindle cells (original magnification X10). D) Immunohistochemical expression of ALK was positive (original magnification X10). E) Immunohistochemical expression of CD-68 showing positivity of histocytes (original magnification X10).

sclerotic foci. Nuclear atypia was not seen. Immunohistochemical analysis was positive for the expression of muscle specific actin (Fig. 2C), anaplastic lymphoma kinase-1 (ALK-1) (Fig. 2D), and CD-68 (Fig. 2E).

A final diagnosis of IMT was made. There was no evidence of recurrence after four months of follow-up (Fig. 3).

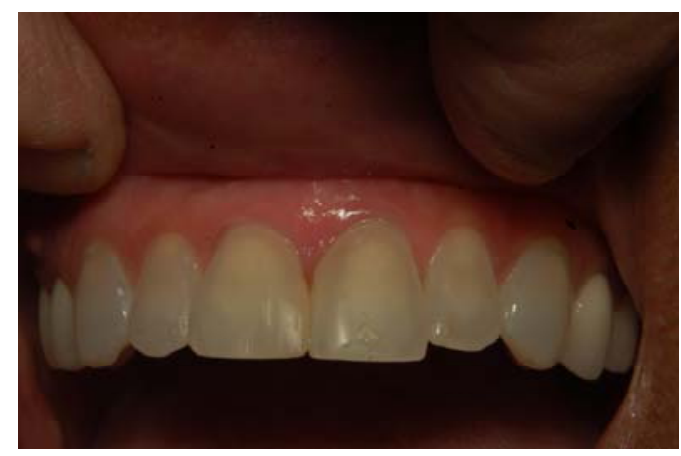

Fig. (3). Postoperative follow up after four months showing complete healing of the gingiva and no signs of recurrence. Note closure of diastema with veneer.

\section{DISCUSSION}

IMT is a tumor lesion consisting of variable numbers of inflammatory cells and myofibroblastic spindle cells [1]. This lesion is rare outside the lung, liver and orbit, with only 22 cases reported in the literature. Liston et al. in 1981 was the first to report IMTs of oral cavity in three children [2]. IMT has been described by various names including inflammatory pseudotumor (IPT), plasma cell granuloma, benign myofibroblastoma, inflammatory fibrosarcoma, histocytoma, xanthomatous granuloma, and spindle cell pseudotumor, describing its heterogeneous nature [2, 3]. Additionally, several histopathologic variants were described by Somersen in 1978 including; xanthogranuloma, plasma cell (plasma cell granuloma), and the sclerosing granulomatous types [5].

The pathogenesis of IMT remains unknown and controversial and recent evidence shows that IMTs may have a different etiology and clinicopathologic features from IPTs in the central nervous system, spleen and lymph nodes $[6,7]$. In intraoral lesions, Brooks et al. distinguished the term IMT, which is a neoplastic process from IPT, which is reactive and reparative process [8]. However, hypotheses suggest that the lesion maybe infectious, autoimmune, syndromic or traumatic in origin. Reports suggest that this tumor in the 
Table 1. Clinical Features of IPT and IMT Cases in Oral Cavity

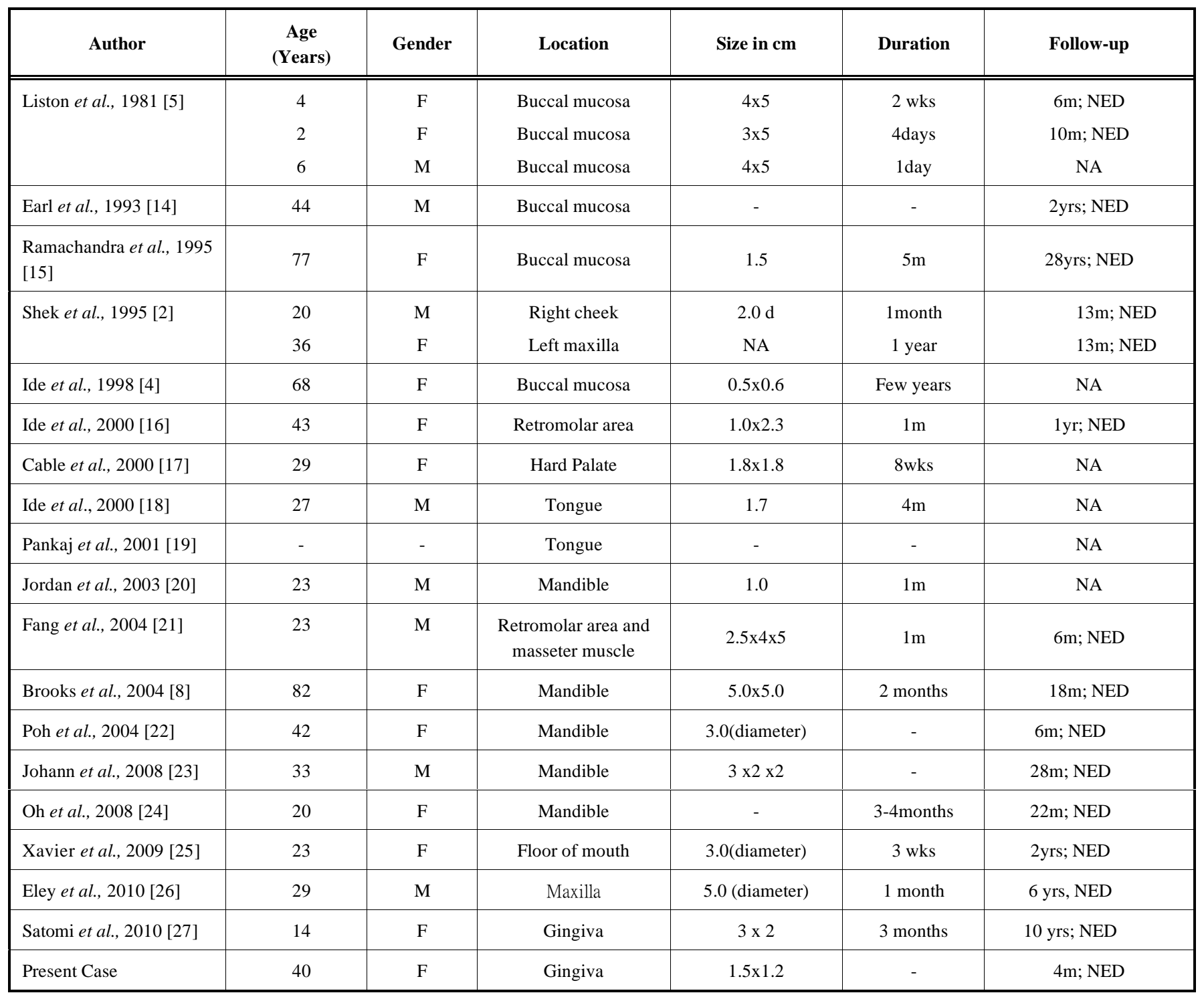

NA, not available; NED, no evidence of disease.

liver maybe associated with inflammatory bowel disease, Papillon-Lefevre syndrome, severe congenital neutropenia (Kostmann's disease), or leukemia [1, 8-11]. HIV infection has also been associated with this neoplasm in various organs $[8,12]$. Interestingly, evidence for a role of EpsteinBarr viruses has been noted in some cases of IMT in liver, spleen and lymph nodes, but the role of human herpesvirus- 8 (HHV8) is not clearly associated [6, 8, 13]. Other organisms found in association with tumor include actinomycetes found in hepatic pseudotumors; or nocardiae and mycoplasma in pulmonary pseudotumors [1].

The terms "inflammatory pseudotumor" and "inflammatory myofibroblastic tumor" were used synonymously in most publications, thus we reviewed all 22 cases diagnosed in the English literature as IPT or IMT including our case (Based on criteria followed by Brooks et al. 2004) Table 1 $[2,4,5,8,14-27]$. The most common intraoral site observed was the buccal mucosa, with lesions occurring over a wide age range 2 to 82 years with a mean of 32 years and showing a 1.6:1 female predilection. The lesion typically presents as a firm, indurated swelling and does not produce significant systemic symptoms, unlike its counterpart in visceral organs $[2,3]$. Intrabony presentation of IMT is rare. Only three cases have been reported $[22,24,26]$. Brooks et al. described a resorptive effect of soft tissue IMT on the underling alveolar bone of edentulous mandible [8]. A CT scan or magnetic resonance imaging was done in previous reports which characterized lesions with ill-defined infiltrative or erosive bony margins $[1,2,24]$.

Histologically, IMT of the oral cavity presents with a variable admixture of fascicles of myofibroblastic spindle cells mixed with acute and chronic inflammatory cells [2]. Atypical mitoses are rare. The stroma is often myxoid or collagenous with prominent vasculature. The histologic differential diagnosis of IMT is extensive, and includes benign and malignant spindle cell tumors such as nodular fasciitis, solitary fibrous tumor, benign fibrous histocytoma, calcify- 
ing fibrous tumor, myofibroma, fibrosarcoma, follicular dendritic cell tumor, and leiomyosarcoma. Histologically, IMTs contain a much more prominent inflammatory infiltrate than nodular fasciitis [13]. Additionally, they lack the "c" shaped fascicles, and mucin-rich stroma which is responsible for the characteristic "tissue culture-like or feathery" appearance in nodular fasciitis [28]. Solitary fibrous tumor was excluded due to the lack of hemangiopericytoma-like areas and strong CD34 immunoreactivity [29]. The diagnosis of benign fibrous histocytoma was not favored because of the lack of characteristic storiform pattern [30]. Calcifying fibrous tumor, a rare benign neoplasm, is uniformly hypocellular and contains scattered dystrophic calcifications [13]. The diagnosis of myofibroma was excluded due to the lack of biphasic growth pattern with hemangiopericytoma-like blood vessels [31].

Fibrosarcoma was excluded due to the lack of malignant features, collagenous areas and herringbone pattern that characterize it. Additionally, it typically lacks a significant inflammatory infiltrate $[31,32]$. Follicular dendritic cell tumor is differentiated from IMT by its characteristic distribution of inflammatory infiltrate admixed with dendritic spindle cells. It is easily distinguished by immunohistochemical staining for $\mathrm{CD} 21, \mathrm{CD} 23$ and/or CD35 [2, 8, 33]. If there was a predominant lymphocytic and/or plasmacytic component, a plasma cell neoplasm (plasmacytoma and multiple myeloma) or lymphoma should be excluded. Mucosaassociated lymphoid tissue-type lymphoma (MALT) may show prominent plasma cell differentiation and should be added to the list of histologic different diagnoses for IMT of salivary glands. No epimyoepithelial islands should be detected, even by immunostaining for cytokeratin, in IMT [1, 34].

In our case, the immunohistochemical analysis revealed that the spindle cells were positive for muscle specific actin, ALK, and histocytes were positive for CD-68. According to the histological and immunohistochemical features of the lesion, a final diagnosis IMT was made.

IMT has shown clonal gene rearrangements of the short arm of chromosome 2, some of which result in an ALK gene rearrangements; such rearrangements are uncommon in adults over 40 years of age with IMT $[3,8,13]$. Lawrence et al. subsequently identified two distinct balanced chromosomal translocations involving the ALK kinase gene. One at chromosome $2 \mathrm{p} 23$ and other involving either the tropomyosin 3 gene (TPM3) at chromosomal locus lq21 or the tropomyosin 4 gene (TPM4) at chromosomal locus 19p13.1, resulting in $\mathrm{t}(1 ; 2)(\mathrm{q} 21 ; \mathrm{p} 23)$ and $\mathrm{t}(2 ; 19)(\mathrm{p} 23 ; \mathrm{p} 13.1)$ translocations, respectively [35]. Other fusion partners of ALK that have been documented in IMT include: cysteinyl-tRNA synthetase (CARS), clathrin heavy chain (CLTC), ran-binding protein 2 (RAN-BP2), 5-aminoimidazole-4-carboxamide ribonucleotide formyltransferase/IMP cyclohydrolase (ATIC), and SEC31 homolog A (S. cerevisiae) (SEC31L1) [36]. CARS gene has been shown to fuse to ALK with a $t(2 ; 11 ; 2)(p 23 ; p 15 ; q 31)$ [37]. Fusion of ALK with CTLC gene localized to $17 \mathrm{q} 23$ was detected in two cases of IMT, while ALK-ATIC chimeric fusion was detected in an IMT of urinary bladder [38, 39]. An intra-abdominal IMT with a novel ALK fusion that involved the RANBP2 gene at $2 \mathrm{q} 13$ and SEC31L1, lead to a novel SEC31L1/ALK fusion gene, with a translocation $\mathrm{t}(2 ; 4)(\mathrm{p} 23 ; \mathrm{q} 21)$ have been reported [40, 41 ]. Frequently, these cytogenetic abnormalities (approximately $50 \%$ of IMTs) result in the overexpression of the ALK protein kinase often determined by immunohistochemistry, and aiding in the diagnosis of IMT. Most other myofibroblastic and fibroblastic tumors are negative for ALK [6, 13]. Other features, such as the presence of ganglion-like cells, atypia, p53 expression and aneuploidy may identify patients with IMT and those at high malignant risk [3].

IMTs are tumors with unpredictable clinical behavior, requiring complete surgical excision and continuous monitoring of clinical consequences [1]. Medical management, including corticosteroids are not effective in head and neck lesions, while considered in the management of orbital IMT $[1,3]$. There is no evidence of recurrence, malignant transformation, metastasis or death reported with oral IMTs [2]. According to the World Health Organization IMTs are classified as tumors of intermediate biological potential due to a tendency of local recurrence and small risk of distance metastasis [13]. IMT in the oral cavity may be confused with other malignant tumors on clinical, radiographic, and histologic appearance. Therefore, it is important to recognize the distinction among them in order to provide better guidelines for treatment and outcome.

\section{REFERENCES}

[1] Narla LD, Newman B, Spottswood SS, Narla, S, Koll, IR. Inflammatory pseudotumor. Radiographics 2003; 23: 719-29.

[2] Shek AW, Wu PC, Samman N. Inflammatory pseudotumour of the mouth and maxilla. J Clin Pathol 1996; 49: 164-7.

[3] Van Weert S, Manni JJ, Driessen A. Inflammatory myofibroblastic tumor of the parotid gland: case report and review of the literature. Acta Otolaryngol 2005; 125: 433-7.

[4] Ide F, Shimoyama T, Horie N. Intravenous myofibroblastic pseudotumour of the buccal mucosa. Oral Oncol 1998; 34: 232-5.

[5] Liston SL, Dehner LP, Jarvis CW, et al. Inflammatory pseudotumors in the buccal tissues of children. Oral Surg Oral Med Oral Pathol 1981; 51: 287-91.

[6] Kutok JL, Pinkus GS, Dorfman DM, et al. Inflammatory pseudotumor of lymph node and spleen: an entity biologically distinct from inflammatory myofibroblastic tumor. Hum Pathol 2001; 32: 1382-7.

[7] Swain RS, Tihan T, Horvai AE, et al. Inflammatory myofibroblastic tumor of the central nervous system and its relationship to inflammatory pseudotumor. Hum Pathol 2008; 39: 410-9.

[8] Brooks JK, Nikitakis NG, Frankel BF, et al. Oral inflammatory myofibroblastic tumor demonstrating ALK, p53, MDM2, CDK4 $\mathrm{pRb}$, and Ki-67 immunoreactivity in an elderly patient. Oral Surg Oral Med Oral Pathol Oral Radiol Endod 2005; 99: 716-26.

[9] Tajima K, Kosugi S, Fuyama S, et al. Multiple inflammatory pseudotumors of the liver associated with acute myeloblastic leukemia. Intern Med 1998; 37: 542-5.

[10] Hsiao CC, Chen CL, Eng HL. Inflammatory pseudotumor of the liver in Kostmann's disease. Pediatr Surg Int 1999; 15: 266-9.

[11] Czauderna P, Sznurkowska K, Korzon M, et al. Association of inflammatory pseudotumor of the liver and Papillon-Lefevre syndrome-case report. Eur J Pediatr Surg 1999; 9: 343-6.

[12] Braun B, Cazorla A, Rivas C, et al. Inflammatory pseudotumor of the spleen in a patient with human immunodeficiency virus infection: a case report and review of the literature. Ann Hematol 2003; 82: 511-4.

[13] Gleason BC, Hornick JL. Inflammatory myofibroblastic tumours: where are we now? J Clin Pathol 2008; 61: 428-37.

[14] Earl PD, Lowry JC, Sloan P. Intraoral inflammatory pseudotumor. Oral Surg Oral Med Oral Pathol 1993; 76: 279-83. 
[15] Ramachandra S, Hollowood K, Bisceglia M, et al. Inflammatory pseudotumour of soft tissues: a clinicopathological and immunohistochemical analysis of 18 cases. Histopathology 1995; 27: 313-23.

[16] Ide F, Shimoyama T, Horie N. Inflammatory pseudotumor in the mandibular retromolar region. J Oral Pathol Med 1998; 27: 50810 .

[17] Cable BB, Leonard D, Fielding CG, Hommer DH. Pathology forum: quiz case 1 . Diagnosis: inflammatory myofibroblastic tumor (IMT). Arch Otolaryngol Head Neck Surg 2000; 126: 900, 904-5.

[18] Ide F, Shimoyama T, Horie N. Sclerosing inflammatory myofibroblastic tumor of the tongue: an immunohistochemical and ultrastructural study. Oral Oncol 2000; 36: 300-4.

[19] Pankaj C, Uma C. How to manage oral inflammatory myofibroblastic tumor (inflammatory pseudotumor)? Oral Dis 2001; 7: 3156 .

[20] Jordan RC, Regezi JA. Oral spindle cell neoplasms: a review of 307 cases. Oral Surg Oral Med Oral Pathol Oral Radiol Endod 2003; 95: 717-24.

[21] Fang JC, Dym H. Myofibroblastic tumor of the oral cavity. A rare clinical entity. N Y State Dent J 2004; 70: 28-30.

[22] Poh CF, Priddy RW, Dahlman DM. Intramandibular inflammatory myofibroblastic tumor:a true neoplasm or reactive lesion? Oral Surg Oral Med Oral Pathol Oral Radiol Endod 2005; 100: 460-6.

[23] Johann AC, Caldeira PC, Abdo EN, Sousa SO, Aguiar MC, Mesquita RA. Inflammatory myofibroblastic tumor of the alveolar mucosa of the mandible. Minerva Stomatol 2008; 57: 59-63.

[24] Oh JH, Yim JH, Yoon BW, Choi BJ, Lee DW, Kwon YD. Inflammatory pseudotumor in the mandible. J Craniofac Surg 2008; 19: 1552-3.

[25] Xavier FC, Rocha AC, Sugaya NN, dos Santos-Pinto D Jr, de Sousa SC. Fibronectin as an adjuvant in the diagnosis of oral inflammatory myofibroblastic tumor. Med Oral Patol Oral Cir Bucal 2009; 1: 635-9.

[26] Eley KA, Watt-Smith SR. Intraoral presentation of inflammatory myofibroblastic tumor (pseudotumor) at the site of dental extraction: report of a case and review of the literature. J Oral MaxillofacSurg 2010; 68: 2016-20.

[27] Satomi T, Watanabe M, Matsubayashi J, Nagao T, Chiba H. A successfully treated inflammatory myofibroblastic tumor of the mandible with long-term follow-up and review of the literature. Med Mol Morphol 2010 ; 43: 185-91.

[28] Dayan D, Nasrallah V, Vered M. Clinico-pathologic correlations of myofibroblastic tumors of the oral cavity: 1. Nodular fasciitis. J Oral Pathol Med 2005; 34: 426-35.
[29] Shimoyama T, Horie N, Ide F. Solitary fibrous tumor of the palate: a case report and review of the literature. J Oral Maxillofac Surg 2004; 62: 895-7.

[30] Alves FA, Vargas PA, Coelho Siqueira SA, et al. Benign fibrous histiocytoma of the buccal mucosa: case report with immunohistochemical features. J Oral Maxillofac Surg 2003; 61: 269-71.

[31] Neville B, Damm D, Allen C, Bouquot J. Oral and Maxillofacial pathology. $3^{\text {rd }}$ ed. Philadelphia: W.B. Saunders 2008.

[32] Vered M, Allon I, Buchner A, et al. Clinico-pathologic correlations of myofibroblastic tumors of the oral cavity. II. Myofibroma and myofibromatosis of the oral soft tissues. J Oral Pathol Med 2007; 36: 304-1437.

[33] Satoh K, Hibi G, Yamamoto Y, et al. Follicular dendritic cell tumor in the oro-pharyngeal region: report of a case and a review of the literature. Oral Oncol 2003; 39: 415-9.

[34] Kojima M, Nakamura S, Itoh $\mathrm{H}$, et al. Inflammatory pseudotumor of the submandibular gland: report of a case presenting with autoimmune disease-like clinical manifestations. Arch Pathol Lab Med 2001; 125: 1095-7.

[35] Lawrence B, Perez-Atayde A, Hibbard MK, et al. TPM3-ALK and TPM4-ALK oncogenes in inflammatory myofibroblastic tumors. Am J Pathol 2000; 157: 377-84.

[36] Coffin CM, Hornick JL, Fletcher CD. Inflammatory myofibroblastic tumor: comparison of clinicopathologic, histologic, and immunohistochemical features including ALK expression in atypical and aggressive cases. Am J Surg Pathol 2007; 31: 509-20.

[37] Cools J, Wlodarska I, Somers R, et al. Identification of novel fusion partners of ALK, the anaplastic lymphoma kinase, in anaplastic large-cell lymphoma and inflammatory myofibroblastic tumor. Genes Chromosomes Cancer 2002; 34: 354-62.

[38] Bridge JA, Kanamori M, Ma Z, et al. Fusion of the ALK gene to the clathrin heavy chain gene, CLTC, in inflammatory myofibroblastic tumor. Am J Pathol 2001; 159: 411-5.

[39] Debiec-Rychter M, Marynen P, Hagemeijer A, et al. ALK-ATIC fusion in urinary bladder inflammatory myofibroblastic tumor. Genes Chromosomes Cancer 2003; 38: 187-90.

[40] Ma Z, Hill DA, Collins MH, et al. Fusion of ALK to the Ranbinding protein 2 (RANBP2) gene in inflammatory myofibroblastic tumor. Genes Chromosomes Cancer 2003; 37: 98-105.

[41] Panagopoulos I, Nilsson T, Domanski HA, et al. Fusion of the SEC31L1 and ALK genes in an inflammatory myofibroblastic tumor. Int J Cancer 2006; 118: 1181-6.

(C) Binmadi et al.; Licensee Bentham Open.

This is an open access article licensed under the terms of the Creative Commons Attribution Non-Commercial License (http://creativecommons.org/licenses/by-nc/3.0/) which permits unrestricted, non-commercial use, distribution and reproduction in any medium, provided the work is properly cited. 